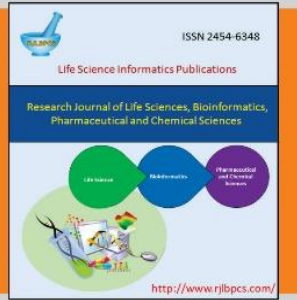

Life Science Informatics Publications

Research Journal of Life Sciences, Bioinformatics, Pharmaceutical and Chemical Sciences

\title{
FORENSIC ODONTOLOGY- A REVIEW
}

\author{
Jatin Gupta, Kanupriya Gupta*
}

Faculty of Dental Sciences, BHU, Varanasi, India

\begin{abstract}
Despite breakthrough in science and technology, natural calamities and crimes continue to persist in human life. Identification of human remains is essential for various reasons including legal, criminal, humanitarian and social grounds. Dental remains can be used for identification as using them is cost effective, reliable and fast. Forensic odontology is a branch of dentistry that analyzes dental evidence to overlap the dental and legal profession. This article reviews the recent advances in the field of forensic odontology while highlighting the role of the dentist in identification of human, dental remains and crime investigation. The concept of using dental evidence in forensic investigation has kindled so much interest in the recent past that forensic odontology is even suggested as the single positive identification method to solve certain forensic cases. In this process, the shortcomings in forensic odontology though few are overlooked. These discrepancies associated with various methods are to be weighed cautiously to make forensic odontology a more accurate, reliable, and reproducible investigatory science. In this paper, we present our understanding of the limitations in various methods employed in forensic odontology.
\end{abstract}

KEYWORDS: Bitemarks, cheiloscopy, forensic odontology, limitations, photographs, radiographs, rugoscopy, toothprints.

\section{Corresponding Author: Dr. Kanupriya Gupta*MDS}

Faculty of Dental Sciences, BHU, Varanasi, India.

Email Address: drkanupriya12@gmail.com

(C) 2018 Life Science Informatics Publication All rights reserved Peer review under responsibility of Life Science Informatics Publications 


\section{INTRODUCTION}

Forensic odontology has been defined as that branch of dentistry which, in the interest of justice, deals with the proper handling and examination of dental evidence and with the proper evaluation and presentation of dental findings. Forensic odontology has played a key role in identification of persons in mass disasters (aviation, earthquakes, Tsunamis), in crime investigation, in ethnic studies, and in identification of decomposed and disfigured bodies like that of drowned persons, fire victims, and victims of motor vehicle accidents. The various methods employed in forensic odontology include rugoscopy, cheiloscopy, bite marks, tooth prints, radiographs, photographic study and molecular methods. Though the shortcomings with these various methods are few, the discrepancies associated with them are to be weighed cautiously to make forensic odontology a more accurate, reliable, and reproducible investigatory science. In this paper, the limitations of various methods employed in forensic odontology are discussed.

\section{STUDY OF PALATAL RUGAE (RUGOSCOPY)}

Palatal rugae comprise about three to seven ridges radiating out tangentially from the incisive papilla. These ridges can be classified as curved, straight, wavy, and branched. The pattern of these rugae is considered unique to an individual. In instances where postmortem dental identification is not possible, as in edentulous mouths, palatal rugae can be used as a supplement. The shortcomings in applying rugoscopy as a definitive tool in forensic odontology are many. Post- mortem identification is not possible without the ante mortem records. Complex rugae patterns (patterns that cannot be classified under one particular group) can cause intra or inter observer errors. Kapali et al.[1] have observed that denture wear, tooth malposition, and palatal pathology can cause alterations in rugae patterns. Further, Thomas et al.[2] have stated that rugae patterns are genetically determined, and so can be rather used in population differentiation than individual identification. In a situation involving fire, palatal rugae are often destroyed, and also since decomposition and skeletonization can occur in less than six weeks in summer and four months in winter, rugoscopy does not have application after this stipulated period.[3]

\section{EXAMINATION OF LIP PRINTS (CHEILOSCOPY)}

The external surface of the lip has numerous elevations and depressions that form a characteristic pattern, referred to as lip prints. Lip prints can be obtained at the crime scene from clothing, cups, glasses, cigarettes, windows and doors. Using lip prints for personal identification in forensic odontology is an accepted method in the criminal justice system worldwide. Impressions are made from the middle portion of the lower lip, an area always visible in any trace made, and the characteristic patterns are studied. The various patterns identified include vertical, intersected, branched, reticular, and undetermined. The anatomical landmarks of the lip include chelion (the lateral most point in mouth opening), stomion (the contact of upper and lower lips in mid-sagital

(C) 2018 Life Science Informatics Publication All rights reserved Peer review under responsibility of Life Science Informatics Publications 
plane), and labrale superius and labrale inferius (the highest and lowest points of upper and lower lip margins in the mid-sagital plane, respectively).Various factors can alter lip print recording. Lip prints have to be obtained within 24 hours of the time of death to prevent erroneous data that would result from post-mortem alterations of lip[4]. Lip print pattern depends on whether the mouth is opened or closed. In closed-mouth position lip exhibits well-defined grooves, whereas in open position the grooves are relatively ill defined and difficult to interpret. Any pathology of the lip such as mucocele or any postsurgical alteration of the lip can change the lip print pattern. Also, loss of support due to loss of anterior teeth can cause changes in lip prints. Any debris or fluid on the lip surface, application of a thick layer of lipstick, or over stretching of cellophane tape can alter lip print recording.[5] Although lip prints are unique to an individual, when the lines are not clear, individual identification based on this trace is extremely difficult unless the trace contains more individual characteristics like scars, clefs, etc.

\section{EXAMINATION OF BITE MARKS}

The science of identification of bite marks is relatively new and potentially valuable in the field of forensic investigation. Based upon the circumstances, bite marks may be deposited within food stuffs, other objects, or on the skin of the victim. Bite marks are circular or ovoid areas of abrasion or contusion, occasionally with associated indentations. It may be composed of two U-shaped arches that are separated at their bases by an open space. The diameter of the injury typically ranges from 25-40 $\mathrm{mm}$ and often a bruise can be seen at the center. Newer techniques that have enhanced bite mark identification include application of electron microscopy and computer enhancement techniques, determination of ABO blood groups from the saliva on the bite mark, and linking bacteria and other microorganisms found in the bite mark to the oral milieu of the perpetrator. The drawbacks encountered in recording bite marks are however many. Due to inherent alterations, the shape and clarity of bite marks found on the skin of the victims change in a relatively short duration (10-20 minutes) both in living and dead, and this necessitates their recording at the earliest possible time. Though photographed immediately, the three-dimensional bite marks on the two- dimensional photograph will be associated with changes in color and spatial relations. Also, incomplete bite marks are not conclusive and a minimum of four to five teeth have to be present for reliable bite mark analysis.[6]Skin not only is associated with curved surfaces but also is a poor medium for impression.[7] Further, it has the intrinsic property of distortion leading to considerable variability in the precision of representation of bite marks. Thus, bite mark recording of skin has to be weighed with caution. Also, the site of bite mark on skin is of prime importance[8] as curved surfaces tend to distort more than flat surfaces and also the accuracy of various impression materials employed has to be analyzed. Bite marks are associated with hemorrhage[9] and post injury edema, which together can alter bite marks evidence. Also, there are instances in which two sets of teeth can match

(C) 2018 Life Science Informatics Publication All rights reserved Peer review under responsibility of Life Science Informatics Publications 
identically with the bite marks. Sometimes ECG electrode application can resemble bite marks and are to be differentiated. As dental features change over time, changes can occur after obtaining ante mortem records. Extraction, trauma, exfoliation, periodontal disease, caries, and prosthesis work can change the configuration of teeth. For this very reason, bite marks are considered less reliable than other biometric methods. Judges and members of the jury usually do not have enough knowledge to assess the scientific merit of new methods and must rely on experts within approved judicial guidelines. Bite mark evidence has been challenged on this basis both because of its perceived lack of scientific merit and its potentially prejudicial aspects. Thus, forensic dentists need to approach bite marks with a certain degree of skepticism and continuously acknowledge their limitations.

\section{EXAMINATION OF TOOTH PRINTS (AMELOGLYPHICS)}

Ameloblasts lay down the enamel rods in an undulating and intertwining path. This is reflected on the outer surface of the enamel as patterns of the ends of series of adjacent enamel rods. This study of the enamel rod end patterns is termed as ameloglyphics by Manjunath et al.[10] and could aid as an identification tool in decomposed or burned bodies as enamel can resist decomposition. This study needs ante mortem records. Though enamel is the hardest mineralized substance in human body, the enamel surface is usually subjected to micro and macrowearing. Fractured, decayed, attrited, abraded, and eroded teeth cannot be included in this method. Ameloglyphics is still in its infancy and whether the tooth prints are the same at different depths of enamel has to be evaluated with further studies.

\section{RADIOGRAPHS}

Dental features do change over time and for this very reason, dental-based identification is considered less reliable compared to other biometric methods like finger prints. But in victims where there is complete decomposition, radiographs may be the only available biometric method. Various morphological and pathological alterations can be studied from the radiographs. In morphology based studies, root morphology comparatively aids better in identification than crown morphology.[11] Apart from routine findings, like decayed, missed, filled, and fractured teeth, various stages of wound healing in extraction sockets, degree of root formation, and bone trabecular pattern in the jaws aid in identification. In our country, ante mortem records are scant and if available are either incomplete or improper. In children, the ante mortem records are all the more scant and the transformation of the dentition from deciduous to permanent set can always mislead. There might be changes after obtaining ante mortem records (like any dental treatment, trauma) which can mislead the investigators. Inherent poor image quality is one of the most anticipated drawbacks. There are difficulties in matching the viewing angles (identical projection, angulation), exposure, and similar magnification in postmortem radiographs to those taken ante mortem. Also, the state of

(C) 2018 Life Science Informatics Publication All rights reserved Peer review under responsibility of Life Science Informatics Publications 
dental remains may entirely preclude the possibility of taking certain types of postmortem radiographs.

\section{PHOTOGRAPHS}

Photographs are valuable substitutes for written records and can overcome language barriers. However, photographs have considerable inherent limitations and stringent requirements are needed for accurate reproduction. The basic difficulty arises when three-dimensional objects are replicated as two-dimensional photographs, which can create distortion, and color change. Photographs are sometimes associated with parallax errors. Lighting, camera orientation, close- up capability, and stability are extremely critical factors while taking photographs. Tripod should support the camera perpendicular to the long axis of the object to be photographed. Photographs without a scale or any circular reference devices may be inherently inaccurate. Small plastic rulers are subject to certain extent of inaccuracy and ABFO scale no.2 is designated as a standard scale.[12]

\section{MOLECULAR METHODS}

Molecular methods are highly accurate, reproducible, and unique, and are extremely reliable in forensic science. Drawbacks however do exist in this relatively new methodology. Errors may develop in sample collection, processing, and interpretation. Any bacterial contamination and second person's DNA can alter the interpretation. While processing, too little amount of DNA can produce less intense bands which can cause misinterpretation of results. Also, degraded samples can produce very scant amount of high molecular weight DNA.

\section{CONCLUSION}

Though forensic odontology has achieved giant strides in recent times, various techniques utilized in forensic odontology are abided by limitations. These limitations are to be kept in mind when answering queries in the court of law while prosecuting an accused, because an improper conclusion can alter and shatter the dreams and lives of alleged accused too.

\section{CONFLICT OF INTEREST}

No conflict of interest exists.

(C) 2018 Life Science Informatics Publication All rights reserved Peer review under responsibility of Life Science Informatics Publications 


\section{REFERENCES}

1. Kapali S, Townsend G, Richards L, Parish T. Palatal rugae patterns in Australian aborigines and caucasians. Aust Dent J 1997;42:129-33.

2. Thomas CJ, Kotze TW Jr. The palatal rugae pattern in six Southern African human populations. J Dent Assoc South Africa 1983;38:547-53.

3. Alberta Kumar DA J Decay rates in a cold climate region: A review of cases involving advanced decomposition from the medical examiner's office in Edmonton. Forensic Sci 1998;43:57-61

4. Utsuno H, Kanoh T, Tadokoro O, Inoue K. Preliminary study of post mortem identifcation using lip prints. Forensic Sci Int 2005; 149:129-32.

5. Sivapathasundharam B, Prakash PA, Sivakumar G. Lip prints (cheiloscopy). Indian J Dent Res 2001;12:234-7.

6. Strom F. Investigation of bite marks. J Dent Res 1963;42:312-6.

7. Rothwell BR. Bite marks in forensic dentistry: A review of legal and scientific issues. J Am Dent Assoc 1995;126:223-32.

8. Rawson RD, Brooks S. Classification of human breast morphology important to bitemark investigation. Ann Forensic Med Pathol 1984;5:19-24.

9. Barbanel JC, Evans JH. Bite marks in skin-mechanical factors J Forensic Sci Soc 1974;14:235-8.

10. Manjunath K, Sriram G, Saraswathi TR, Sivapathasundharam B. Enamel rod end pat- terns: A preliminary study using acetate peel technique and automated biometrics J Forensic Odontol 2008;1:33-6.

11. SA Sholl, Moody GH. Evaluation of dental radiographic identification: An experimental study. Forensic Sci Int 2001;115:165-9.

12. Ebert JI. Discussion of the bitemark standard reference scale-ABFO No-2. J Forensic Sci 1988;33:301-4.

(C) 2018 Life Science Informatics Publication All rights reserved Peer review under responsibility of Life Science Informatics Publications 